\title{
Processing of Body Odor Signals by the Human Brain
}

\author{
Bettina M. Pause
}

Received: 4 October 2011 / Accepted: 25 November 2011 /Published online: 10 December 2011

(C) The Author(s) 2011. This article is published with open access at Springerlink.com

\begin{abstract}
Brain development in mammals has been proposed to be promoted by successful adaptations to the social complexity as well as to the social and non-social chemical environment. Therefore, the communication via chemosensory signals might have been and might still be a phylogenetically ancient communication channel transmitting evolutionary significant information. In humans, the neuronal underpinnings of the processing of social chemosignals have been investigated in relation to kin recognition, mate choice, the reproductive state and emotional contagion. These studies reveal that human chemosignals are probably not processed within olfactory brain areas but through neuronal relays responsible for the processing of social information. It is concluded that the processing of human social chemosignals resembles the processing of social signals originating from other modalities, except that human social chemosignals are usually communicated without the allocation of attentional resources, that is below the threshold of consciousness. Deviances in the processing of human social chemosignals might be related to the development and maintenance of mental disorders.
\end{abstract}

Keywords Body odor - Brain imaging · Chemosensory communication $\cdot$ Emotional contagion $\cdot$ Social brain

\section{Introduction}

« L'odeur d'un corps, c'est ce corps lui-même que nous aspirons par la bouche et le nez, que nous possédons d'un

B. M. Pause $(\bowtie)$

Department of Experimental Psychology,

University of Duesseldorf,

Universitaetsstraße 1,

40225 Duesseldorf, Germany

e-mail: bettina.pause@uni-duesseldorf.de seul coup, comme sa substance la plus secrète et, pour tout dire, sa nature. L'odeur en moi, c'est la fusion du corps de l'autre à mon corps. Mais c'est ce corps désincarné, vaporisé, resté, certes, tout entier lui-même, mais devenu esprit volatil. » (Sartre 1947, p. 201) ${ }^{1}$.

In his essay about the French lyricist Charles Baudelaire, Sartre literarily describes the process of body odor perception in humans. Even though body odor is made of physically describable matter, it can be regarded as an indicator of the impermanence of being because it is also highly volatile. Hence, the existentialist understands body odor to be a unique composition out of being and nothingness. Therefore, in the view of Sartre, the human body odor symbolizes the true nature of human beings. Accordingly, during the smelling process, the soul and the body of an individual are incorporated by the perceiver. As a result, the perceiver's soul and body merge with the soul and body of the odor sender.

Just recently, the perception of human body odors has been investigated by use of methods of the modern neurosciences. Whereas the question whether body odor resembles the true human nature might remain subject to further philosophical debates; however, the neurosciences may help to answer the question, whether chemicals derived from human body fluids are capable of changing the feelings and cognitions of the perceiver. In the following, it will be discussed whether chemical communication in humans is related to the transmission of information relevant for

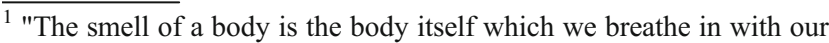
nose and mouth, which we suddenly possess as though it were its most secret substance and, to put the matter in a nutshell, its nature. The smell which is in me is the fusion of the body of the other person with my body; but it is the other person's body with the flesh removed, a vaporized body which has remained completely itself but which has become a volatile spirit." (Sartre 1967, p. 174).
} 
ontogenetic and phylogenetic survival. Evolutionary theories even point to the possibility that the complexity of the human brain, at least in part, derived from the ability to perceive, process and adapt to social chemosignals of conspecifics.

\section{Social Communication}

Social behavior is ubiquitous in the animal kingdom and essential for the survival of diverse mammalian species. Social behavior includes attraction of potential mates, the regulation of social distance, the soothing and restoring of social equilibrium, and the engendering of help from conspecifics. All of these social actions seem to be associated with the experience of basic emotions (Levenson 2003) in humans and other mammals (Burgdorf and Panksepp 2006; Panksepp 2011). Whereas the successful operation of such social actions obviously supports phylogenetic survival, it has recently been stated that social complexity was the main promotor of the primate's brain size (Dunbar 1998). A growing number of different studies coherently report that the neocortex in anthropoid primates increases with different indicators of social complexity, e.g., group size, grooming clique size, the frequency of coalitions, and the prevalence of social play (see Dunbar and Shultz 2007a). While predation risk has been postulated as the ultimate cause for group living (Dunbar and Shultz 2007b), social enrichment requires the development of behavioral flexibility, which in turn is essential for the formation of stable social bonds. Within the neocortex, the volume of the ventromedial prefrontal area has been considered to be intimately linked to social competencies in humans (Lewis et al. 2011). In addition, besides coding the biological significance of stimuli in general (Pessoa and Adolphs 2010), the amygdala seems to be the main paleocortical relay for the processing of social information in primates (Emery and Amaral 2000; Sallet et al. 2011) and humans (Bickart et al. 2011).

Social communication is based upon a successful release and processing of different sensory signals, including speech, touch, biological motion, facial expressions, and chemosensory signals. In comparison to the communication via other sensory modalities, social communication through chemosensory signals has several advantages (Wyatt 2003). Chemosensory signals can be used in darkness and can easily cross barriers. Depending on the volatility of the molecules, chemosensory signals might be transmitted across very long distances. In contrast, low volatile molecules might still keep the information for conspecifics at the place of release, while the sender has already disappeared (Pause et al. 1997). Hereby, solely the communication through chemical signals is proficient to carry information about social events that happened in the past. Furthermore, social chemical signals are usually based on a specific mixture of molecules, while the meaning of the signal not only depends on the molecules within the mixture but also on the concentration of each molecule. Therefore, the number of signals which could carry social information is extremely high.

The processing of and reaction to environmental chemical signals might have been of special importance for the evolution of the vertebrate brain. Even as early as 1904, it was proposed that the telencephalon was originally an olfactory structure invaded by other sensory systems over the course of vertebrate evolution (Edinger 1904). In fact, the brains of the jawless fish, the modern representatives of the most primitive vertebrates, lampreys, and hagfish, are dominated by huge olfactory bulbs (Eisthen 1997; Northcutt 2002). The view that the olfactory system of the jawless fish (lamprey) represents the most ancient version of the vertebrate olfactory system is supported by sequence analyses of the olfactory receptor gene family (Freitag et al. 1999). Furthermore, recent highresolution X-ray computed tomography of fossil mammalian skulls indicates that the special features of the mammalian brain evolved through the improved ability of mammals to analyze and process the complex olfactory environment (Rowe et al. 2011). During successive evolutionary pulses, first, the olfactory bulb and olfactory (piriform) cortex expanded. About 200 million years ago, a species which resembles the basal-most member of Mammaliaformes (Morganucodon) showed a first major pulse in encephalization, with a brain about $50 \%$ larger than that of earlier related mammal-like reptiles. This encephalization was mainly due to the expansion of the olfactory bulbs. A second encephalization pulse was assessed in the closest known fossil relative of living mammals (Hadrocodium) and was again associated with a marked increase in brain size, and especially of the olfactory bulbs and the cerebral hemispheres. Finally, the huge olfactory receptor genome developed, which was accompanied by olfactory epithelial growth. It can be concluded from these findings that the ability to optimally adjust to the chemical environment was far more important for the huge encephalization in mammals than the ability to process visual or auditory stimuli.

In summary, evidence is accumulating that during vertebrate and mammalian evolution, the ability to adjust to the chemical complexity of the social and non-social environment was the main or one of the main forces for brain development. In primates, however, social complexity has been considered to be the main promotor of neocortex development. It could be speculated, that social chemical communication in humans is still highly complex and important for phylogenetic survival and successful development. The role of chemical communication in humans 
might have been strongly underestimated as chemical communication between humans usually does not reach the level of conscious processing. However, it is commonly agreed, that in order to adjust to the environmental social requirements, social signals commonly require a fast and automatic response and are therefore mostly processed implicitly without the allocation of attentional resources (Frith and Frith 2008; Öhman and Mineka 2001; Tamietto and de Gelder 2010). In the long run, the investigation of human chemosensory communication will show how deeply the chemical senses are involved in human communication. In fact, first reports suggest that even highly sophisticated social emotions, like moral disgust, might have their evolutionary origin in the processing of chemical signals (Chapman et al. 2009; for a controversial view see Herz 2011).

\section{Body Odor Signals}

Whereas body odors can derive from different body fluids (urine, vaginal secretions, sperm, tears) the products of the glandular systems in the skin have usually been considered to be valid sources of human body odor (for an exception see Gelstein et al. 2011). Out of the three primary gland systems, the sebaceous glands, the eccrine glands and the apocrine glands, the sweat produced by the apocrine glands has received most attention. The apocrine glands are located primarily round the nipples, genitals and the axillary region. They develop fully in puberty and are unique to humans and great apes. Apocrine sweat glands secrete a variety of odor precursors that are transformed into volatile odoriferous substances by bacterial enzymes on the skin surface. The secretion of the aprocrine gland is adrenergic innervated through sympathetic fibers. Therefore, the secretion is related to autonomic activation which in turn is associated with motivational or emotional experiences.

A signal can be defined as a stimulus which carries a message to a receiver. Within social communication, the signal is produced and released by a sender. Thus, in contrast to a pure stimulus, which may or may not carry relevant information, a social signal always conveys specific information between two individuals. Therefore, in understanding human communication, it is necessary to focus on the transmitted information, which can be isolated easiest by analyzing the effect of the communication in the signal receiver. So far, four areas of human chemosensory communication have been studied in more detail, each demonstrating physiological and/ or behavioral consequences of signal perception in the receiver. They are related to kin recognition, mate selection, menstrual cycle synchronicity, and emotional contagion.

Kin recognition is most important for structuring social relations in many diverse species (see Mehdiabadi et al.
2006). In order to promote inclusive fitness, which can be understood as the successful transmission of one's own and relatives' genes to the next generation, pro-social behavior is favored among family members (Hamilton, 1964). However, unrelated individuals, like out-group members are more easily perceived as aversive (Olsson et al. 2005) and more easily attacked (De Dreu et al. 2010). Given the importance of kin recognition, numerous studies have shown that newborns are able to chemosensorily identify their mothers, that mothers and fathers are able to chemosensorily identify their children, that siblings recognize each other by smell, and that even unrelated individuals are able to match family members by smell (see Porter 1999; Porter and Schaal 2003).

Similar to kin recognition, a successful mate selection, which forms the basis for the production of healthy offspring, is also a necessary prerequisite for phylogenetic survival. The major histocompatibility complex (MHC) is a highly polymorphic gene complex. It encodes glycoproteins that deliver peptides to the cell surface during antigen presentation, thereby creating histocompatibility or self identification for the immune system. It has been shown in several species that the individual MHC-type is associated to an individual body odor profile, which can be used to chemosensorily discriminate between conspecifics. Fertile individuals prefer the body odors of partners with a relatively dissimilar MHC type to their own. This preference, in turn, seems to be one of the major reasons for mate selection in many vertebrates (Boehm and Zufall 2006; Restrepo et al. 2006). It has been proposed that this differential mating helps to maintain the high MHC polymorphism within species. A high MHC polymorphism enables the species members to resist to a broader array of pathogens, which is crucial for survival. In reference to the immunological function of the MHC, in humans, it is called human leukocyte antigen (HLA). Humans seem not only to exert body odor preferences for HLA dissimilar individuals but also to preferentially select partners who possess a relatively different HLA type (Havlicek and Roberts 2009; Jacob et al. 2002). Thus, HLA-associated body odors seem to be used as signals for mate choice.

Another research field in human chemosensory communication is related to the phenomenon of menstrual synchrony. Some 40 years ago, McClintock found that women living or spending time together show a synchronized menstrual cycle (McClintock 1971). About 30 years later, it could be demonstrated that this phenomenon is most probably due to the communication of menstrual cycle related chemosignals (Stern and McClintock 1998). Whereas odorless axillary sweat samples of women in the follicular cycle phase shortened the menstrual cycle of the female recipients, chemical signals derived from sweat samples of women in the ovulatory 
cycle phase lengthened the menstrual cycle phase of the signal receivers. This study was the first to show that not only the behavior, but also the endocrine status in humans is prone to be influenced by human chemosignals. However, the evolutionary significance of synchronized menstrual cycles in women is still debated (Mc Clintock 2002; Schank 2001).

The most recently discovered area of chemosensory communication in humans is related to the detection of danger and emotional contagion. It is common across the animal kingdom that stressed individuals inform their conspecifics via chemosignals about a potential harm (e.g., a predator attack). Even though the release of the signal is associated with an increased risk for the sender to encounter direct threat, the development of this communication might have been evolutionary successful, because all signal receiving conspecifics benefit from signal perception. In rodents, the release of chemosensory alarm signals is associated with activity of the pituitary-adrenal axis and secretion of adrenocorticotropin (ACTH; Abel 1994). Physiological reactions to these signals within the receiver resemble stress-related adaptations (Fanselow 1985; Kikusui et al. 2001; Moynihan et al., 2000). Therefore, it is postulated that the experience of stress can be chemosensorily transmitted from the sender to the receiver.

Across phyla, the perception of such stress-related chemosignals seems to be associated with avoidance of the odor source and immediate withdrawal behavior (von Frisch 1941; Mackay-Sim and Laing 1981; Müller-Velten 1966; Ressler et al. 1968; Suh et al. 2004; Zalaquett and Thiessen 1991). A reliable indicator of the activation of motor systems related to withdrawal behavior is the startle reflex. The startle reflex can be measured in animals (Davis et al. 1993) and humans (Lang et al. 1990) and is increased during states of negative affect and decreased during states of positive affect. As rats (Inagaki et al. 2008, 2009) and humans (Pause et al. 2009, Prehn et al. 2006) show an augmented startle response in the context of chemical stress signals, it is concluded that motor systems related to signal avoidance are automatically primed through the perception of stressrelated chemosignals of conspecifics.

Besides the effects on motor behavior, the perception of stress-related chemosignals significantly alters the perception of visual social signals in humans. In the context of chemosensory stress signals, the perceptual acuity to happy facial expressions is reduced (Pause et al. 2004; Zernecke et al. 2011), and the perceptual acuity to negative facial expressions is increased (fear: Zhou and Chen 2009; anger: Mujica-Parodi et al. 2009). Moreover, when presented in the context of chemosensory stress signals, neutral or ambiguous facial expressions attract additional attentional resources (Rubin et al. 2011). Thus, chemosignals related to stress or other negative emotional states reliably alter visual social perception: the acuity for social signals related to safety is reduced while at the same time the acuity for social signals related to harm is increased.

In summary, several studies impressively demonstrate that human body odors convey important social signals. These signals deliver information about kinship, immunogenetic mating characteristics, the endocrine status, and emotional states reflecting potential transient danger. In fact, social communication might be one of the most important functions of chemosensory perception in humans (Stevenson 2009). It should be added that the behavioral significance of single substances (e.g., androgen steroids) which can be detected in human body fluids is far less obvious. This is not surprising, taking into account that usually mixtures of several compounds, which are active only in a certain concentration range, form the biologically active signal (Wyatt, 2003). Therefore, several authors conclude, that in humans, behaviorally relevant properties of single molecules have as yet not been demonstrated (Doty 2010; Pause, 2004a,b; Wyatt 2009; Wysocki and Preti 2004).

\section{Neuronal Processing of Body Odor Signals}

So far, the neuronal processing of body odors has been investigated using the event-related potential (ERP) technique, positron emission tomography (PET), and functional magnetic resonance imaging (fMRI). ERPs are the averaged epochs of the electroencephalogram (EEG) that occur timelocked to the presented stimuli. As long as chemosensory stimuli elicit the ERP, the term chemosensory ERP (CSERP) has been applied. Latency and amplitude of the CSERP components provide information about early, pre-attentive, and late evaluative stimulus processing. The CSERP technique offers a very high temporal resolution, but only a poor spatial resolution. By use of the PET technique, biochemical components of neural transmission can be detected, e.g., the regional glucose uptake. As compared to fMRI, the temporal resolution is much and the spatial resolution slightly lower. The fMRI method provides an indirect measure of neural activity measuring the blood flow. This method has the highest spatial resolution and also a relatively good temporal resolution.

In the investigation of olfaction a number of studies could repeatedly demonstrate the activation of primary (piriform cortex, amygdala, entorhinal cortex) and secondary olfactory brain structures (hippocampus, hypothalamus, thalamus, orbitofrontal cortex, insula) through odors (Sobel et al. 2003). While the primary olfactory cortex is composed out of areas receiving direct input from the olfactory bulb, areas of the secondary olfactory cortex are directly connected to brain areas of the primary olfactory cortex. 
Processing of HLA-Associated Body Odors

CSERP analyses revealed that body odors of donors with a similar HLA type to the perceiver are processed faster and activate more neuronal resources than body odors of donors with a dissimilar HLA type to the perceiver (Pause et al. 2006). Whereas rating studies on body odor preferences (e.g., Wedekind and Füri 1997) and studies on mating behavior in humans (e.g. Ober et al. 1997) could only report a correlative relationship between the HLA system and the relevant indicators of behavior, this was the first experimental study to demonstrate that the brain preferentially processes information about HLA similarity over information about HLA dissimilarity. The evidence of this study suggested that the behavioral impact of chemosensory signals related to HLA similarity might be stronger than of signals related to HLA dissimilarity. As the HLA loci are the most polymorphic loci in the human genome (Parham \& Ohta 1996), the probability of meeting unrelated individuals with a dissimilar HLA type is extremely high. Therefore, the development of a preference for potential partners with a dissimilar HLA type might be related to other factors than to chemosensory cues, whereas the rejection of potential partners with a similar or identical HLA type might be most effectively determined by the rarely occurring chemosignals of self. Furthermore, it has been proposed that MHC-regulated inbreeding avoidance might lead to higher fitness benefits than MHC heterozygosity (Penn 2002). Accordingly, inbreeding avoidance could be successfully achieved if $\mathrm{MHC}$ similarity is transmitted as a signal activating avoidance behavior. Therefore, in humans, HLA-related signals seem to be associated with a negative selection bias in mating behavior.

\section{Processing of Body Odors of Kin and Non-Kin}

So far, one PET study investigated whether body odor of kin is processed differently from body odor of non-kin (Lundström et al. 2009). Even though the participants could not consciously differentiate between the body odors of their sisters and their friends, the regional cerebral blood flow was higher in the fronto-temporal junction, the insula, and the dorsomedial prefrontal cortex during kin recognition. The activation of the dorsomedial prefrontal cortex is discussed to be related to self-referent stimulus processing during kin recognition (Lundström et al. 2009; Lundström and Olsson 2010). Thus, this study provides further evidence that genetic similarity is recognized through an automatic selfreferential process and is therefore in line with the CSERP result that processing immunogenetic similarity is biologically more relevant than processing immunogenetic dissimilarity (Pause et al. 2006). The study further demonstrates, that kin is chemosensorily recognized by the human brain without the allocation of attentional resources. This result is in line with the well known phenomenon that social signals are usually processed implicitly (Frith and Frith 2008).

Processing of Body Odors Related to the Reproductive State

Even though the phenomenon of the communication of the reproductive state between women (Stern and McClintock 1998) has not been investigated using brain imaging techniques so far, one study investigated indirectly whether an increase in the level of sexual hormones in men can be detected chemosensorily by the female brain (Zhou and Chen 2008). Axillary sweat was collected from men while watching video segments showing sexual intercourse between heterosexual couples. As compared to axillary sweat collected during an emotionally neutral situation, the sex related sweat was primarily processed within the orbitofrontal and the fusiform cortex and within the hypothalamus. The authors concluded that the activation of the hypothalamus and the orbitofrontal cortex could be related to the processing of the emotional significance of the stimuli. Activation of the fusiform cortex is often related to the processing of social signals (faces, voices, or body gestures) and could be due to the social nature of the stimuli.

Processing of Body Odors Related to Different Emotional States

Two brain imaging studies and one CSERP study investigated whether and how stress- or anxiety-related sweat is processed by the human brain. Stress-related sweat was obtained from first-time skydivers (Mujica-Parodi et al. 2009), and anxiety-related sweat was collected from university students waiting for their final oral examination in order to reach an academic degree (Pause et al. 2010; Prehn-Kristensen et al. 2009).

The CSERP study showed that the processing of almost odorless chemosensory anxiety signals requires enhanced neuronal energy (P3 amplitude) originating from medial frontal brain areas (Pause et al. 2010). This effect was more pronounced in females than in males, which could be due to the fact that females show a processing advantage for social emotional stimuli (Proverbio et al. 2008) and in addition for stimuli with a weak perceptional salience (Li et al. 2008).

As compared to sweat samples collected in an emotionally neutral sport condition, sweat samples collected in the anxiety condition activate brain areas involved in the processing of social emotional stimuli (fusiform gyrus) and in the regulation of empathic feelings (insula, precuneus, cingulate cortex). In this study, the odors were hardly detectable and could not be differentiated regarding their intensity, pleasantness, unpleasantness, or familiarity. Thus, again, it 
was shown that the human brain automatically guides physiological adjustments to chemosensory social signals, without being dependent on conscious mediation. It was further concluded that in contrast to other modalities, the physiological adjustments in response to chemosensory anxiety signals seem to be mainly related to an automatic contagion of the feeling. This interpretation is in line with the startle experiments, showing an automatic activation of withdrawalrelated motor systems (Pause et al. 2009; Prehn et al. 2006), as well as with animal data, suggesting a chemosensory transmission of stress from sender to perceiver. Finally, the speculation of Sartre (1947) on the consequences of body odor perception might be a fruitful basic approach to the investigation of chemical communication in humans because the phenomenon of emotional contagion through human chemosignals could in fact literally be described as an incorporation of the sender's soul and body.

In contrast to the anxiety study, the stress-related sweat was mainly processed within the amygdala (Mujica-Parodi et al. 2009). As the odors in this study were perceived as weak with a comparable emotional valence, and could not be consciously distinguished, the authors excluded the possibility that the differences in brain activity were due to odor characteristics. However, extreme physiological and psychological stress is not related to a specific emotion but activates a diverse set of physiological systems related to a mixture of different positive (e.g., surprise, joy) and negative emotions (e.g., disgust, fear). It is therefore reasonable to assume that the perception of stress-related chemosignals does not activate emotion and empathy-specific neuronal networks but only less specific structures which prime non-specific autonomic adjustments.

\section{Discussion}

The studies on the neuronal processing of human body odor reveal that social chemosensory signals are processed in the human brain differently from common odors (Lundström et al. 2008). Instead, human social chemosignals seem to be processed in brain areas related to the processing of social information, such as the fusiform cortex (social chemosignals: Prehn-Kristensen et al. 2009; Zhou and Chen 2008; relay of social signal processing: LaBar et al. 2003; Hadjikhani and de Gelder 2003), the cingulate cortex (social chemosignals: Lundström et al. 2008; Prehn-Kristensen et al. 2009; relay of social signal processing: Völlm et al. 2006), and the insular cortex (social chemosignals: Lundström et al. 2009; Prehn-Kristensen et al. 2009; relay of social signal processing: Singer and Lamm 2009). Moreover, also activations within the medial prefrontal cortex (Lundström et al. 2009) and the amygdala (Mujica-Parodi et al. 2009) could be related to the processing of significant social signals (Bechara et al. 2002).

In line with the consideration that successful social communication is a prerequisite for the unique development of the mammalian brain (Dunbar 1998), a new branch of science evolved in the neuroscience during the last decade, called the social neurosciences (Cacioppo and Berntson 2005). Meanwhile, the most intriguing progress generated by this new research area may be related to the finding of specialized neural networks within the human brain, which are responsible for the processing of social information (Adolphs 2010). Hereby, it has been demonstrated that the perception of other humans' facial expression is different from the perception of common visual objects (fusiform face area, Kanwisher et al. 1997). Moreover, social touch, building the basis for the forming of lasting relationships and bonding, might also be processed as a unique social signal (Dunbar 2010; Morrison et al. 2010). Finally, social feelings, like empathy, require the processing in specialized neuronal relays, different from common non-social feelings (Singer and Lamm 2009).

In comparison with the processing of social signals from other modalities, it would be highly unlikely for human social chemosignals to be processed similar to common odors. In fact, all studies investigating the processing of natural complex human chemosignals found neuronal networks involved, which are specialized for the processing of social rather than olfactory information. It is up to future research to investigate whether the specialized network responsible for the processing of human chemosignals within the central nervous system has a correlate in a specialized receptor system for social chemosignals (Brechbühl et al. 2008; Liberles and Buck 2006).

In order to understand human communication via chemosignals, several phenomenons are waiting for their exploration, e.g., the question which kind of body fluid most effectively conveys social information. Due to the presence of apocrine glands within the axillary region, which are considered to significantly influence the composition of socially relevant chemosignals (Heckmann et al. 2003), commonly axillary sweat has been used as the chemosensory stimulus. However, it is also likely that other human body fluids, like tears, contribute to a successful chemosensory communication between humans (Gelstein et al. 2011).

Furthermore, chemosensory communication may include much more evolutionary significant information than those investigated so far by brain imaging studies. For example, chemosensory signals most probably convey information related to the actual health status (Arakawa et al. 2011; Havlicek and Lenochova 2006). Furthermore, the communication of social emotions is probably not restricted to the 
communication of stress, but might also include other emotions, like sadness (Gelstein et al. 2011) or social competition (Adolph et al. 2010).

Finally, the analysis of the conditions responsible for an impaired communication via chemosignals might be of special interest in understanding deviant behavior and deviant mental states in humans. For example, it has been shown that individuals scoring high in social anxiety process human chemosignals differently (Zhou et al. 2011) and less effectively (Pause et al. 2009, 2010) than non-anxious controls. Therefore, the knowledge of human chemosensory communication might even improve the knowledge about the development and therapy of mental disorders.

\section{Conclusion}

It can be concluded, that human social chemosignals are processed as cues for significant behavioral adaptations which are meaningful in terms of evolutionary consequences. Through the communication of chemosignals, social bonds can be formed and maintained (kin recognition), the health status of the immune system in the population is optimized (MHC-associated chemosignals), and relevant changes in motivational (reproductive behavior) and emotional systems are successfully transmitted between conspecifics. The latter is of special importance whenever information about potential harm has to be spread across conspecifics efficiently, automatically and in a lasting manner.

Acknowledgements We are grateful to Sabine Schlösser for proofreading the manuscript.

Open Access This article is distributed under the terms of the Creative Commons Attribution Noncommercial License which permits any noncommercial use, distribution, and reproduction in any medium, provided the original author(s) and source are credited.

\section{References}

Abel EL (1994) The pituitary mediates production or release of an alarm chemosignal in rats. Horm Behav 28:139-145

Adolph D, Schlösser S, Hawighorst M, Pause BM (2010) Chemosensory signals of competition increase the skin conductance response in humans. Physiol Behav 101:666-671

Adolphs R (2010) Conceptual challenges and directions for social neurosciences. Neuron 65:752-767

Arakawa H, Cruz S, Deak T (2011) From models to mechanisms: odorant communication as a key determinant of social behavior in rodents during illness-associated states. Neurosci Biobehav Rev 35:1916-1928

Bechara A, Tranel D, Damasio AR (2002) The somatic marker hypothesis and decision making. In: Grafman J (ed) Handbook of Neuropsychology, vol 7, 2nd edn. Elsevier, Amsterdam, pp 117143
Bickart KC, Wright CI, Dautoff RJ, Dickerson BC, Feldman Barrett L (2011) Amygdala volume and social network size in humans. Nature Neurosci 14:163-164

Boehm T, Zufall F (2006) MHC peptides and the sensory evaluation of genotype. Trends Neurosci 29:100-107

Brechbühl J, Klaey M, Broillet MC (2008) Grueneberg ganglion cells mediate alarm pheromone detection in mice. Science 321:1092-1095

Burgdorf J, Panksepp J (2006) The neurobiology of positive emotions. Neurosci Biobehav Rev 30:173-187

Cacioppo JT, Berntson GG (eds) (2005) Social neurosciences. Psychology Press, New York

Chapman HA, Kim DA, Susskind JM, Anderson AK (2009) In bad taste: evidence for the oral origins of moral disgust. Science 323:1222-1226

Davis M, Falls WA, Campeau S, Kim M (1993) Fear-potentiated startle: a neural and pharmacological analysis. Behav Brain Res 58:175-198

De Dreu CK, Greer LL, Handgraaf MJ, Shalvi S, Van Kleef GA, Baas M, Ten Velden FS, Van Dijk E, Feith SW (2010) The neuropeptide oxytocin regulates parochial altruism in intergroup conflict among humans. Science 328:1408-1411

Doty RL (2010) The great pheromone myth. The John Hopkins University Press, Baltimore

Dunbar RIM (1998) The social brain hypothesis. Evol Anthrop 6:178-190

Dunbar RIM (2010) The social role of touch in humans and primates: behavioural function and neurobiological mechanisms. Neurosci Biobehav Rev 34:260-268

Dunbar RIM, Shultz S (2007a) Evolution of the social brain. Science 317:1344-1347

Dunbar RIM, Shultz S (2007b) Understanding primate brain evolution. Phil Trans R Soc Lond 362B:649-658

Edinger L (1904) Bau der nervösen Zentralorgane des Menschen und der Tiere. Vogel, Leipzig

Eisthen HL (1997) Evolution of the vertebrate olfactory system. Brain Behav Evol 50:222-233

Emery NJ, Amaral DG (2000) The role of the amygdala in primate social cognition. In: Lane RD, Nadel L (eds) Cognitive neuroscience of emotions. Oxford University Press, New York, pp 156-191

Fanselow MS (1985) Odors released by stressed rats produce opioid analgesia in unstressed rats. Behav Neurosci 99:589-592

Freitag J, Beck A, Ludwig G, von Buchholtz L, Breer H (1999) On the origin of the olfactory receptor family: receptor genes of the jawless fish (Lampetra fluviatilis). Gene 226:165-174

Frisch KV (1941) Über einen Schreckstoff der Fischhaut und seine biologische Bedeutung. Z Vergl Physiol 29:46-145

Frith CD, Frith U (2008) Implicit and explicit processes in social cognition. Neuron 60:503-510

Gelstein S, Yeshurun Y, Rozenkrantz L, Shushan S, Frumin I, Roth Y, Sobel N (2011) Human tears contain a chemosignal. Science 331:226-230

Hadjikhani N, de Gelder B (2003) Seeing fearful body expressions activates the fusiform cortex and amygdala. Curr Biol 13:2201-2205

Hamilton WD (1964) The genetical evolution of social behaviour: I \& II. J Theor Biol 7:1-52

Havlicek J, Lenochova P (2006) The effect of meat consumption on body odor attractiveness. Chem Senses 31:747-752

Havlicek J, Roberts SC (2009) MHC-correlated mate choice in humans: a review. Psychoneuroendocrinol 34:497-512

Heckmann M, Teichmann B, Pause BM, Plewig G (2003) Amelioration of body odor after intracutaneous axillary injection of Botulinum Toxin A. Arch Dermatol 139:57-59

Herz R (2011) PROP taste sensitivity is related to visceral but not moral disgust. Chem Percept 4:72-79

Inagaki H, Kiyokawa Y, Kikusui T, Takeuchi Y, Mori Y (2008) Enhancement of the acoustic startle reflex by an alarm pheromone in male rats. Physiol Behav 93:606-611 
Inagaki H, Nakamura K, Kiyokawa Y, Kikusui T, Takeuchi Y, Mori Y (2009) The volatility of an alarm pheromone in male rats. Physiol Behav 96:749-752

Jacob S, McClintock MK, Zelano B, Ober C (2002) Paternally inherited HLA alleles are associated with women's choice of male odor. Nat Genet 30:175-179

Kanwisher N, McDermott J, Chun MM (1997) The fusiform face area: a module in human extrastriate cortex specialized for face perception. J Neurosci 17:4302-4311

Kikusui T, Takigami S, Takeuchi Y, Mori Y (2001) Alarm pheromone enhances stress-induced hyperthermia in rats. Physiol Behav 72:45-50

LaBar KS, Crupain MJ, Voyvodic JT, McCarthy G (2003) Dynamic perception of facial affect and identity in the human brain. Cereb Cortex 13:1023-1033

Lang PJ, Bradley MM, Cuthbert BN (1990) Emotion, attention, and the startle reflex. Psychol Rev 97:377-395

Levenson RW (2003) Autonomic specificity and emotion. In: Davidson RJ, Scherer KR, Goldsmith HH (eds) Handbook of affective sciences. Oxford University Press, Oxford, pp 212-224

Lewis PA, Rezaie R, Brown R, Roberts N, Dunbar RI (2011) Ventromedial prefrontal volume predicts understanding of others and social network size. Neuroimage 57:1624-1629

Li H, Yuan J, Lin C (2008) The neural mechanism underlying the female advantage in identifying negative emotions: An eventrelated potential study. Neuroimage 40:1921-1929

Liberles SD, Buck LB (2006) A second class of chemosensory receptors in the olfactory epithelium. Nature 442:645-650

Lundström JN, Boyle JA, Zatorre RJ, Jones-Gotman M (2008) Functional neuronal processing of body odors differs from that of similar common odors. Cereb Cortex 18:1466-1474

Lundström JN, Boyle JA, Zatorre RJ, Jones-Gotman M (2009) The neuronal substrates of human olfactory based kin recognition. Hum Brain Mapp 30:2571-2580

Lundström JN, Olsson MJ (2010) Functional neuronal processing of human body odors. Vitam Horm 83:1-23

Mackay-Sim A, Laing GD (1981) Rat's responses to blood and body odors of stressed and non-stressed conspecifics. Physiol Behav 27:503-510

McClintock MK (1971) Menstrual synchrony and suppression. Nature 229:244-245

Mc Clintock MK (2002) Pheromones, odors, and vasanas: the neuroendocrinology of social chemosignals in humans and animals. In: Pfaff DW, Arnold AP, Etgen AM, Fahrbach SE, Rubin RT (eds) Hormones, brain and behavior, vol 1. Academic Press, San Diego, pp 797-870

Mehdiabadi NJ, Jack CN, Farnham TT, Platt TG, Kalla SE, Shaulsky G, Queller DC, Strassmann JE (2006) Social evolution: kin preference in a social microbe. Nature 442:881-882

Morrison I, Löken LS, Olausson H (2010) The skin as a social organ. Exp Brain Res 204:305-314

Moynihan JA, Karp JD, Cohen N, Ader R (2000) Immune deviation following stress odor exposure: role of endogenous opioids. $\mathrm{J}$ Neuroimmunol 102:145-153

Müller-Velten H (1966) Über den Angstgeruch bei der Hausmaus. Z Vergl Physiol 52:401-429

Mujica-Parodi LR, Strey HH, Frederick B, Savoy R, Cox D, Botanov Y, Tolkunov D, Rubin D, Weber J (2009) Chemosensory cues to conspecific emotional stress activate amygdala in humans. PLoS One 4:e6415

Northcutt RG (2002) Understanding vertebrate brain evolution. Integ Comp Biol 42:743-756

Ober C, Weitkamp LP, Cox N, Dytch H, Kostyu D, Elias S (1997) HLA and mate choice in humans. Am J Hum Genet 61:497-504

Öhman A, Mineka S (2001) Fears, phobias, and preparedness: toward an evolved module of fear and fear learning. Psychol Rev 108:483-522
Olsson A, Ebert JP, Banaji MR, Phelps EA (2005) The role of social groups in the persistence of learned fear. Science 309:785-787

Panksepp J (2011) The basic emotional circuits of mammalian brains: do animals have affective lives? Neurosci Biobehav Rev 35:1791-1804

Parham P, Ohta T (1996) Population biology of antigen presentation by MHC class I molecules. Science 272:67-74

Pause BM (2004a) Are androgen steroids acting as pheromones in humans? Physiol Behav 83:21-29

Pause BM (2004b) Is the human skin a pheromone-producing organ? J Cosm Dermatol 3:223-228

Pause BM, Adolph D, Prehn-Kristensen A, Ferstl R (2009) Startle response potentiation to chemosensory anxiety signals in socially anxious individuals. Int J Psychophysiol 74:88-92

Pause BM, Haberkorn K, Eggert F, Müller-Ruchholtz W, Bestmann HJ, Ferstl R (1997) Fractionation and bioassay of human odor types. Physiol Behav 61:957-961

Pause BM, Krauel K, Schrader C, Sojka B, Westphal E, MüllerRuchholtz W, Ferstl R (2006) The human brain is a detector of chemosensorily transmitted HLA-class I similarity in same- and opposite-sex relations. Proc R Soc Lond B 273:471-478

Pause BM, Lübke K, Laudien JH, Ferstl R (2010) Intensified neuronal investment in the processing of chemosensory anxiety signals in non-socially anxious and socially anxious individuals. PLoS ONE 5:e10342

Pause BM, Ohrt A, Prehn A, Ferstl R (2004) Positive emotional priming of facial affect perception in females is diminished by chemosensory anxiety signals. Chem Senses 29:797-805

Penn DJ (2002) The scent of genetic compatibility: sexual selection and the major histocompatibility complex. Ethology 108:1-21

Pessoa L, Adolphs R (2010) Emotion processing and the amygdala: from a 'low road' to 'many roads' of evaluating biological significance. Nat Rev Neurosci 11:773-782

Porter RH (1999) Olfaction and human kin recognition. Genetica 104:259-263

Porter RH, Schaal B (2003) Olfaction and the development of social behavior in neonatal mammals. In: Doty RL (ed) Handbook of olfaction and gustation, 2nd edn. Marcel Dekker, New York, pp 309-327

Prehn A, Ohrt A, Sojka B, Ferstl R, Pause BM (2006) Chemosensory anxiety signals augment the startle reflex in humans. Neurosci Lett 394:127-130

Prehn-Kristensen A, Wiesner C, Bergmann TO, Wolff S, Jansen O, Mehdorn HM, Ferstl R, Pause BM (2009) Induction of empathy by the smell of anxiety. PLoS One 4:e5987

Proverbio AM, Zani A, Adorni R (2008) Neural markers of a greater female responsiveness to social stimuli. BMC Neurosci 9:56

Ressler RH, Cialdini RB, Ghoca ML, Kleist SM (1968) Alarm pheromone in the earthworm Lumbricus terrestris. Science 161:597599

Restrepo D, Lin W, Salcedo E, Yamazaki K, Beauchamp G (2006) Odortypes and MHC peptides: complementary chemosignals of MHC haplotype? Trends Neurosci 29:604-609

Rowe TB, Macrini TE, Luo ZX (2011) Fossil evidence on origin of the mammalian brain. Science 332:955-957

Rubin D, Botanov Y, Hajcak G, Mujica-Parodi LR (2011) Secondhand stress: inhalation of stress sweat enhances neural response to neutral faces. Soc Cogn Affect Neurosci. doi:10.1093/scan/ nsq097

Sallet J, Mars RB, Noonan MP, Andersson JL, O'Reilly JX, Jbabdi S, Croxson PL, Jenkinson M, Miller KL, Rushworth MF (2011) Social network size affects neural circuits in macaques. Science 334:697-700

Sartre J-P (1947) Baudelaire, 3rd edn. Éditions Gallimard, Paris. English edition: Sartre J-P (1967) Baudelaire (trans: Turnell M). A New Directions Paperbook, New York 
Schank JC (2001) Measurement and cycle variability: re-examining the case for ovarian-cycle synchrony in primates. Behav Processes $56: 131-146$

Singer T, Lamm C (2009) The social neuroscience of empathy. Ann N Y Acad Sci 1156:81-96

Sobel N, Johnson BN, Mainland J, Yousem DM (2003) Functional neuroimaging of human olfaction. In: Doty RL (ed) Handbook of olfaction and gustation. Marcel Dekker, New York, pp 251-273

Stern K, McClintock MK (1998) Regulation of ovulation by human pheromones. Nature 392:177-179

Stevenson RJ (2009) An initial evaluation of the functions of human olfaction. Chem Senses 35:3-20

Suh GS, Wong AM, Hergarden AC, Wang JW, Simon AF, Benzer S, Axel $\mathrm{R}$, Anderson DJ (2004) A single population of olfactory sensory neurons mediates an innate avoidance behaviour in Drosophila. Nature 431:854-859

Tamietto M, de Gelder B (2010) Neural bases of the non-conscious perception of emotional signals. Nature Rev Neurosci 11:697-709

Völlm BA, Taylor AN, Richardson P, Corcoran R, Stirling J, McKie S, Deakin JF, Elliott R (2006) Neuronal correlates of theory of mind and empathy: a functional magnetic resonance imaging study in a nonverbal task. Neuroimage 29:90-98
Wedekind C, Füri S (1997) Body odour preferences in men and women: do they aim for specific MHC combinations or simply heterozygosity? Proc R Soc B 264:1471-1479

Wyatt TD (2003) Pheromones and animal behaviour: communication by smell and taste. Cambridge University Press, Cambridge

Wyatt TD (2009) Fifty years of pheromones. Nature 457:262-263

Wysocki CJ, Preti G (2004) Facts, fallacies, fears, and frustrations with human pheromones. Anatom Rec A 281A:1201-1211

Zalaquett C, Thiessen D (1991) The effects of odors from stressed mice on conspecific behaviour. Physiol Behav 50:221-227

Zernecke R, Haegler K, Kleemann AM, Albrecht J, Frank T, Linn J, Brückmann H, Wiesmann M (2011) Effects of male anxiety chemosignals on the evaluation of happy facial expressions. J Psychophysiol 25:116-123

Zhou W, Chen D (2008) Encoding human sexual chemosensory cues in the orbitofrontal and fusiform cortices. J Neurosci 28:1441614421

Zhou W, Chen D (2009) Fear-related chemosignals modulate recognition of fear in ambiguous facial expressions. Psychol Sci 20:177183

Zhou W, Hou P, Zhou Y, Chen D (2011) Reduced recruitment of orbitofrontal cortex to human social chemosensory cues in social anxiety. Neuroimage 55:1401-1406 